\title{
Management of dabigatran-induced bleeding: expert statement
}

\author{
Dietmar Fries - Alexander Giurea - Manfred Gütl · Walter-Michael Halbmayer • \\ Sibylle Kozek-Langenecker · Andreas Pachucki · Franz Roithinger · \\ Barbara Steinlechner · Heinrich Thaler · Ansgar Weltermann
}

Received: 7 March 2013 / Accepted: 8 September 2013 / Published online: 12 November 2013

(C) The Author(s) 2013. This article is published with open access at Springerlink.com

Summary The interdisciplinary group of experts has compiled a clinical guidance for manifest dabigatraninduced haemorrhage and envisaged invasive interventions on patients under dabigatran. It recommends an escalation of treatment measures as summarized in a pocket guide (see electronic supplementary material online and insert in the print issue).

Keywords Thrombin time $\cdot$ Ccarin clotting time $\cdot$ Patient blood management · Haemodialysis · Prothrombincomplex concentrate $\cdot$ Recombinant factor VIIa

\section{Management bei Dabigatran-induzierter Blutung - Expertenempfehlung}

Zusammenfassung Die interdisziplinäre Expertengruppe hat einen klinischen Leitfaden für das Vorgehen bei manifester Dabigatran-induzierter Blutung und bei anstehenden invasiven Eingriffen bei Patienten unter Dabigatran zusammengestellt. Es wird ein eskalierendes Vorgehen vorgeschlagen und in einer Karte für die Manteltasche zusammengefasst (siehe "Electronic supplementary material" online und Beilage in der Print-Ausgabe).

Schlüsselwörter Thrombinzeit · Ecarin clotting time · Patient Blood Management · Hämodialyse · Prothrombinkomplexkonzentrat · rekombinanter Faktor VIIa
Electronic supplementary material: The online version of this article (doi: 10.1007/s00508-013-0430-3) contains supplementary material, which is available to authorized users.

Univ.-Doz. Dr. S. Kozek-Langenecker, MBA ( $\square)$ Department of Anesthesia and Intensive Care,

Evangelical Hospital Vienna, Hans-Sachs-Gasse 10-12, 1180 Wien, Austria

e-mail: sibylle.kozek@aon.at

\section{Fries}

Department of Anesthesia and Intensive Care, Medical University Innsbruck, Innsbruck, Austria

\section{A. Giurea}

Department of Orthopedics,

Medical University of Vienna, Vienna, Austria

\section{Gütl}

Department of Anesthesiology and Intensive Care, Medical University Graz, Graz, Austria

W.-M. Halbmayer

Institute of Laboratory Medicine,

Krankenhaus Hietzing, Vienna, Austria

\section{A. Pachucki}

Department of Trauma Surgery,

Landesklinikum Amstetten, Amstetten, Austria

F. Roithinger

Department of Internal Medicine,

Landesklinikum Mödling, Mödling, Austria

B. Steinlechner

Department of Anesthesia,

General Intensive Care and Pain Management, Medical University of Vienna, Vienna, Austria

\section{H. Thaler}

Trauma Centre Meidling, Division of Internal Medicine, AUVA-Unfallkrankenhaus Meidling, Vienna, Austria

\section{A. Weltermann}

Department of Internal Medicine,

Krankenhaus Elisabethinen, Linz, Austria 


\section{Introduction}

Not least on account of demographic developments, the number of patients receiving oral anticoagulants is constantly increasing [1]. Accordingly, in case of elective and semi-elective surgery, there is an increasing need for a perioperative risk benefit assessment of whether anticoagulation should be continued, discontinued, or "bridged" parenterally. In case of continued oral anticoagulation perioperatively and in case of acute surgery severe bleeding episodes may require rapid inhibition of the biological action of the anticoagulant (reversal). Emergency reversal may also be indicated after injuries and spontaneous non-surgical bleeding. Such measures should be taken in due consideration of the situation, i.e. depending on the severity of the (risk of) haemorrhage, and balancing the risks of haemorrhage and thrombosis in view of the pre-existing indication for chronic anticoagulation. For Vitamin $\mathrm{K}$ antagonists, long-standing experience is available, although at a low level of scientific evidence [2,3]. Such experience and evidence on perioperative management and practical clinical bleeding management is, however, still lacking for the new oral anticoagulants (NOACs; more recently also referred to as direct oral anticoagulants, DOACs). Dabigatran etexilate is the longest-standing NOAC registered for chronic application. Accordingly, the management of dabigatran-induced haemorrhagic complications is currently a frequent clinical and interdisciplinary challenge.

Currently available expert statements permit only an incomplete insight into the complexity of the management of dabigatran-induced haemorrhages, particularly in terms of the classification of haemorrhages according to acuity and severity, as well as the escalating indication for multi-modal therapies and the availability of therapy monitoring methods [4]. Therefore, the objective of the present interdisciplinary group of experts was to prepare recommendations for the management of dabigatraninduced bleeding in the course of day-to-day clinical work. The resulting expert opinion reflects the medical knowledge, specific experience, evaluations and opinions of the authors. As with all expert statements, each of these recommendations will have to be revised over time as new evidence and experience is gained. It should also be noted that use of the proposed recommendations will not guarantee therapeutic success or the absence of complications.

The present expert recommendation does not focus on presenting fundamental knowledge of the pharmacology of dabigatran and the research required for registration since such reviews are readily available [4-8]. For this reason, we merely recapitulate the facts relevant for prophylactic and therapeutic management of bleeding.

\section{Background information on dabigatran}

\section{Action mechanism and pharmacology}

Dabigatran is an oral, reversible direct thrombin inhibitor (DTI) that inhibits both free and fibrin-bound thrombin and thrombin-induced platelet aggregation [5, 6]. After adsorption, non-specific plasma esterases transform the inactive prodrug dabigatran etexilate into the active substance in both plasma and liver. Its mean terminal half-life has been stated to be 14-17 h but may be longer postoperatively [9]. As the drug is primarily eliminated by the kidneys, the half-life is significantly prolonged in patients with renal insufficiency [10]. For this reason, renal function should be monitored at regular intervals (e.g. twice a year) whenever dabigatran is used for longterm therapy [11]. Contraindications against the use of dabigatran are a creatinine clearance $<30 \mathrm{ml} / \mathrm{min}$, artificial heart valves, allergies, haemorrhages, liver disease affecting survival, spontaneous or pharmacologically induced impairment of haemostasis. A dose reduction of Pradaxa $^{\circledR}$ (from $2 \times 150 \mathrm{mg}$ to $2 \times 110 \mathrm{mg}$ per os or from $220 \mathrm{mg}$ to $150 \mathrm{mg}$ per os) is indicated in patients with a creatinine clearance of $30-50 \mathrm{ml} / \mathrm{min}$, concomitant administration of verapamil, in the presence of thrombopathy/thrombopenia, gastroesophageal reflux disease and in patients aged 80 years or older.

On account of its low tendency to bind to plasma proteins, $62-68 \%$ of the active substance can be eliminated by haemodialysis within 2-4 h [4]. It may be assumed that dabigatran can also be removed by haemofiltration and haemodiafiltration, though elimination times are likely to be longer $(>4 \mathrm{~h})$.

\section{Efficacy and approval}

The randomised phase-III study RELY relevant for regulatory approval investigated the efficacy of dabigatran $(2 \times 110 \mathrm{mg} / 2 \times 150 \mathrm{mg})$ vs. warfarin in preventing stroke and systemic embolism in 18,113 patients suffering from atrial fibrillation in combination with at least one additional risk factor for stroke [12], with the occurrence of stroke or embolism serving as primary endpoint. At the higher dosage level, the administration of dabigatran resulted in a significantly lower incidence of haemorragic and ischaemic strokes as compared with warfarin, and the incidence of cardiovascular deaths was also significantly lower. Dabigatran at $2 \times 150 \mathrm{mg}$ is so far the only direct oral anticoagulant causing a significant reduction of ischaemic strokes, which is numerically the most relevant threat. However, no significant difference was found with regard to overall mortality. As far as patient safety was concerned, it should be noted that life-threatening haemorrhages, most importantly intracranial haemorrhage, occurred significantly less often in patients receiving dabigatran at either dosage level than in those treated with warfarin [12]. 
In Austria, dabigatran has been approved under the trade name Pradaxa ${ }^{\circledR}$ for primary prevention of venous thromboembolic events in adult patients following elective surgery for hip or knee joint replacement at a dosage level of $220 \mathrm{mg} 1 \mathrm{x}$ a day or $150 \mathrm{mg} \mathrm{lx}$ a day, as well as for the prevention of strokes or embolisms in non-valvular atrial fibrillation at a level of $150 \mathrm{mg} 2 \mathrm{x}$ a day or $110 \mathrm{mg} 2 \mathrm{x}$ a day. Dabigatran is recommended as a 'first-line' therapy for this chronic indication [13].

\section{Coagulation tests}

No laboratory analyses are required for routine monitoring during dabigatran therapy [6]. Under certain clinical conditions, however, it may be advisable to test for the new anticoagulants, for instance in cases of suspected accidental overdosing, acute bleeding complications, invasive emergency interventions, drug interaction, renal insufficiency, critically ill patients, advanced age and to check compliance.

\section{Routine coagulation tests}

Depending on the dosage administered and the time between the last administration and blood sampling, dabigatran may significantly affect the results of all conventional coagulation tests [14]. Accordingly, the diagnostic acuity of routine coagulation tests is impaired when preoperative patients treated with dabigatran are tested for other hereditary or acquired coagulopathies. Prolonged routine lab tests will not provide specific and quantitative information on the causation or level of dabigatran and could also be due to other haemostatic disorders or substances [14].

A combination of a highly pathological prothrombin time (INR > 2) and a highly pathological activated partial thromboplastin time (aPTT $>90 \mathrm{~s}$ ) at the trough level may suggest (but cannot prove) possible overdosing of dabigatran [15]. According to the manufacturer (SMPC, January 2013), a double or triple prolongation of the aPTT values dabigatran at trough level may be associated with an increased bleeding risk. The thrombin time (TT) is prolonged even at low dabigatran plasma levels, thus a normal TT can be assumed to rule out a clinically relevant dabigatran level.

The least influence on routine coagulation tests can be expected at the trough level of dabigatran $12 \mathrm{~h}$ after the last or immediately before the next administration. To avoid misinterpretations and possibly wrong therapeutic decisions it is therefore imperative, when requesting routine coagulation tests for patients treated with dabigatran, to inform the laboratory of the last time the drug was administered.

\section{Dabigatran-sensitive tests}

Dabigatran-sensitive coagulation tests performed shortly before surgery could best provide information on the extent of the residual pharmacological coagulation inhibition caused by dabigatran [4]. In principle, this information could be obtained by means of the adapted thrombin time (e.g. the Hemoclot ${ }^{\circledR}$ Test) or the ecarin clotting time (ECT). The determination of the adapted TT is based on the inhibition of a defined constant thrombin concentration in diluted plasma samples. On account of their linear dose-effect relation the adapted thrombin time and ECT permit, when calibrated in line with CE standards, a quantitative determination of the effect of dabigatran, whereas the correlation of these dabigatransensitive tests with the clinical outcome parameters of haemorrhages is yet unclear. According to the manufacturer (SMPC, January 2013), a double or triple prolongation of the aPTT values dabigatran at trough level may $\geq 200 \mathrm{ng} / \mathrm{ml}$ in the Hemoclot ${ }^{\circledR}$ Test may be associated with an increased bleeding risk in non-surgical patients. Most importantly, a threshold limit value for the Hemoclot ${ }^{\circledR}$ Test, which predicts a low perioperative bleeding risk, has not yet been established.

\section{Individual risk of thromboembolism and haemorrhage}

Individual risks vary with the magnitude and nature of surgery (expositional risk factors) and individual (dispositional) risk factors. The bleeding risk of non-surgical patients can be assessed by means of the HAS-BLED Score, with a score of $\geq 3$ being generally seen as indicative of an increased risk of haemorrhage [16]. Postoperative bleeding risk and possible strategies to control bleeding will also depend on the experience of the medical care personnel and on locally available resources.

One well-established approach to the stratification of the risks of thromboembolism and stroke is the use of the $\mathrm{CHADS}_{2}$ Score and the $\mathrm{CHA}_{2} \mathrm{DS}_{2}$-VASc Score [17]. In cases of atrial fibrillation with a fairly low $\mathrm{CHA}_{2} \mathrm{DS}_{2}$-VASc Score $(\leq 4)$ and a negative history concerning a thromboembolic event anticoagulation with dabigatran may be discontinued for up to 1 week without causing a clinically relevant increase in the thromboembolism rate.

With pending indications for the use of dabigatran in patients with deep vein thrombosis or pulmonary embolism $[18,19]$, bleeding complications may and will occur in this cohort as well. Nevertheless, the longer treatment and the higher dosage will, in general, always be applied to patients with atrial fibrillation. Therefore, the risks of haemorrhage may possibly be extrapolated to these new indications.

\section{Management of bleeding in patients receiving dabigatran}

Strategies recommended for the management of manifest bleeding in patients receiving dabigatran have been summarised in Fig. 1. 
Fig. 1 Management of manifest bleeding under dabigatran

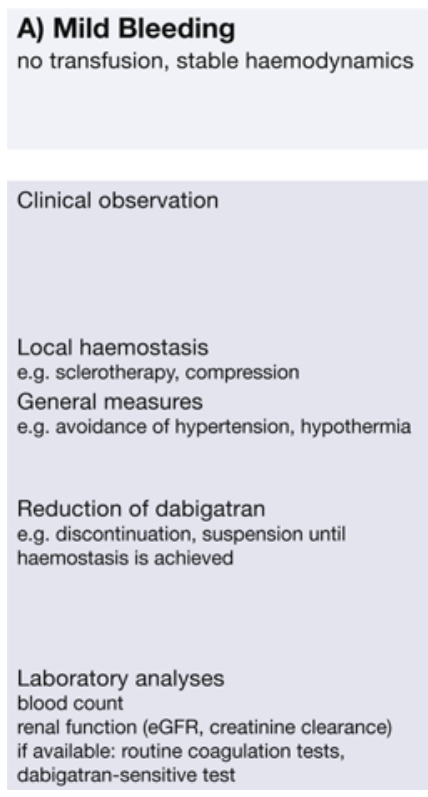

B) Severe Bleeding

$<4$ erythrocyte concentrates haemodynamically stable without catecholamines
C) Life-threatening or organ-threatening Bleeding $\geq 4$ erythrocyte concentrates, catecholamine demand

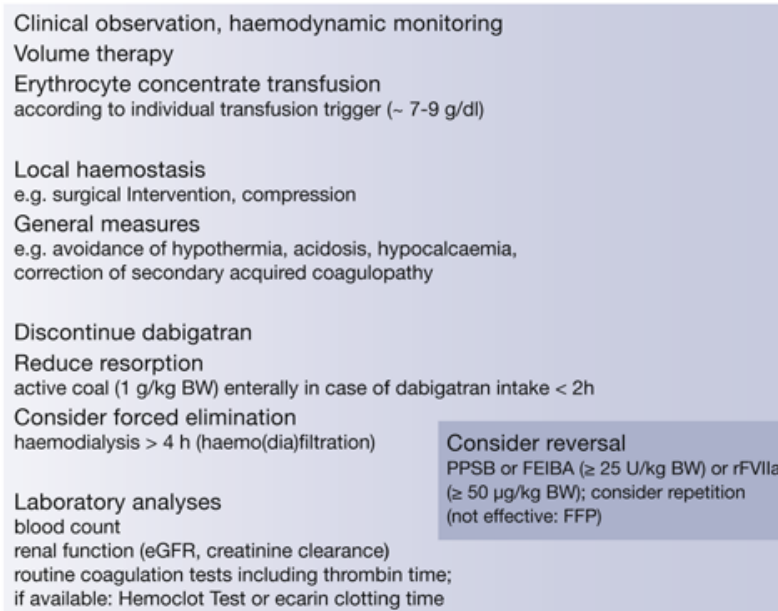

\section{Mild bleeding}

\section{Definition}

The term mild bleeding (e.g. superficial bleeding, diverticular bleeding) describes haemorrhages that do not require transfusions, are haemodynamically irrelevant and can be staunched easily.

\section{Basic measures}

Basic measures comprise general clinical observation of the haemorrhagic patient including haemodynamic monitoring and local haemostasis. The latter can be achieved by such means as mechanical compression or sclerotherapy on condition that the area of bleeding is accessible. Other basic measures are the avoidance of arterial pressure peaks, hypothermia, etc.

\section{Administration of dabigatran}

Until haemostasis has been achieved, patients may require skipping of one or more dosages of dabigatranall on condition that the increased risk of thrombosis does not outweigh the current risk of bleeding. If anticoagulation with dabigatran has been discontinued, it can be resumed within $72 \mathrm{~h}$ once haemostasis has been achieved, in particular if the relapse risk is considered to be low and that of thromboembolism high.

\section{Laboratory tests}

A blood count analysis (including a platelet count) or, if the same is not readily available, the determination of the haematocrit/haemoglobin values by blood gas analysis may be used to exclude haemorrhages requiring blood transfusion. A renal function test (determination of creatinine clearance by the Cockroft-Gault formula, glo- merular filtration rate eGFR using the MDRD formula) may be useful to estimate the risk of dabigatran accumulation. Before resuming dabigatran therapy in patients with renal insufficiency care should be taken to modify, if necessary, the dosage and/or review the indication for dabigatran.

In the case of spontaneous minor bleeding it does not appear imperative to routinely perform laboratory coagulation tests. Excessively prolonged coagulation times may, however, be seen as an indicator of possible overdosing requiring further diagnostic (dabigatran level determination, exploration of other coagulopathies) and therapeutic action (review of dabigatran dosage and its indication).

\section{Strategies not recommended}

On the basis of a risk/benefit assessment in cases of mild bleeding it is not advisable to use coagulation factor concentrates in an attempt to reverse dabigatran action. The use of tranexamic acid for mild haemorrhages does not appear useful in the absence of any association with the pathomechanism of dabigatran-induced bleeding.

In view of the fact that mild bleeding complications can usually be managed by other means, general measures to reduce dabigatran resorption and stimulating elimination are not recommended.

\section{Severe bleeding}

\section{Definition}

Severe bleeding is defined as haemorrhages that require transfusion but, in terms of their haemodynamic relevance, do not appear to require catecholamines and are not deemed immediately life-threatening or organ-threatening. 


\section{Basic measures}

In the case of heavy bleeding (e.g. psoas muscle bleeding) it is recommended to control symptoms by individualised volume replacement for the purpose of achieving haemodynamic stabilisation and to transfuse erythrocyte concentrates on the basis of individualised transfusion triggers. Mostly the transfusion trigger should not exceed $9 \mathrm{~g} / \mathrm{dl}$ nor be lower than $7 \mathrm{~g} / \mathrm{dl}$ [20]. Depending on the extent of bleeding, invasive haemostatic methods, e.g. surgical or radiologic/endovascular interventions, should be considered. As a basic principle, it is advisable to avoid hypothermia, acidosis and hypocalcaemia. Correction of secondarily acquired coagulopathies (e.g. hyperfibrinolysis by antifibrinolytics, factor deficits by coagulation factor concentrates) may be undertaken in line with current trauma guidelines [21,22].

\section{Administration of dabigatran}

In the case of severe bleeding dabigatran should be discontinued until haemostasis has been achieved; once this is the case, anticoagulation with dabigatran can be resumed with an appropriate safety window of 3 days to 2 weeks.

In the case of recent oral dabigatran intake (within the last $2 \mathrm{~h}$ ) enteral administration of activated coal $(1 \mathrm{~g} / \mathrm{kg} \mathrm{BW})$ is recommended, which will bind the substance and reduce resorption [23]. Moreover, dabigatran can be eliminated by haemodialysis.

\section{Laboratory tests}

A blood count analysis (including a platelet count) or, if the same is not readily available, the determination of the haematocrit/haemoglobin values by blood gas analysis is recommended, since it will allow targeted erythrocyte transfusion and avoid transfusion in excess of the individual transfusion triggers.

In the case of severe bleeding requiring transfusion it is recommended to perform routine coagulation tests (with blood samples preferably at dabigatran trough level) in order to rule out (not yet) evaluated hereditary or acquired coagulation disorders if the bleeding was not (or not exclusively) caused by dabigatran. Prolonged thrombin times may lead to evaluation of dabigatran levels (e.g. Hemoclot ${ }^{\circledR}$ Test).

A renal function test (eGFR, creatinine clearance) will permit conclusions regarding possible accumulations that will help adapt the dosage once haemostasis has been achieved. The indication for dabigatran therapy should be checked before administration is resumed.

\section{Strategies not recommended}

In the case of severe bleeding that is not life-threatening and does not jeopardise an organ function, emergency dabigatran reversal by means of coagulation factor concentrates is not recommended because this might, without further benefit for the patient, compound the manifest risk of haemorrhage with an additional risk of a thromboembolic event.

\section{Life-threatening or organ-threatening bleeding}

\section{Definition}

The borderline between massive and life-threatening haemorrhages is blurred but can be arbitrarily defined by the need for transfusion with $\geq 4$ erythrocyte concentrates and the administration of exogenous catecholamins (noradrenalin, adrenalin, dobutamine) for the purpose of haemodynamic stabilisation. Diagnosis of an organ-threatening haemorrhage depends also on the localisation of the lesion, e.g intracerebral, intraspinal or intraocular and the risk of the intervention(s) to achieve local haemostasis.

\section{Basic measures, administration of dabigatran and laboratory tests}

Cases of life-threatening or organ-threatening bleeding should be managed in the same way as severe bleeding (see severe bleeding section above); in addition, the feasibility of emergency measures to offset dabigatran action (emergency reversal) should be considered. In the absence of clinical evidence for emergency reversal of dabigatran only few experimental studies and pharmacological data are available and suggest that the action of dabigatran might, at least partially, be offset by activated prothrombin complex concentrate (e.g. factor eight bypassing activity FEIBA) or recombinant factor VIIa [23-28]. To date no dose-finding studies have been published for this indication. Should reversal be planned, an initial dose of at least $25 \mathrm{U} / \mathrm{kg}$ BW FEIBA or at least $50 \mu \mathrm{g} / \mathrm{kg}$ BW rFVIIa (NovoSeven ${ }^{\circledR}$ ) could be considered, possibly with a repeated administration. Considering the strong increase in thrombin generation induced by these activated coagulation factor concentrates they should be used only after careful benefit/risk assessment. Costeffectiveness of FEIBA and rFVIIa for the reversal of dabigatran has not yet been proven. Furthermore, FEIBA and rVIIa, or experience with their use, are not available in all hospitals.

Conventional prothrombin complex concentrate (PCC) (Beriplex ${ }^{\circledR} 50 \mathrm{U} / \mathrm{kg} \mathrm{BW)}$ stopped bleeding in an animal experiment [26] but heparin-free PCC $\left(\right.$ Cofact $^{\circledR} 50$ $\mathrm{U} / \mathrm{kg} \mathrm{BW)} \mathrm{could} \mathrm{not} \mathrm{reverse} \mathrm{clotting} \mathrm{times} \mathrm{in} \mathrm{six} \mathrm{volun-}$ teers after 2.5 days dabigatran intake [27]. Clinical outcome parameters of bleeding were not assessed in this volunteer trial [27]. PCC is listed in monodisciplinary recommendations as a reversing agent [7]. National data recorded by the NOAC Line (www.oegari.at) suggest favourable results with PCC, so that an attempted reversal with PCC may be seen as a possible therapeutical option if bleeding is deemed life-threatening or organ-threatening. 
Fig. 2 Management of patients under dabigatran during surgical interventions

Elective Surgery
Minor bleeding risk
Continue dabigatran
Clinical observation
Vigilance of surgical team
High bleeding risk
Discontinue dabigatran:
$\quad$ creatinine clearance $>80 \mathrm{ml} / \mathrm{min}$ :
$\quad 2$ days
creatinine clearance $50-80 \mathrm{ml} / \mathrm{min}$ :
$\quad 3$ days
creatinine clearance $30-50 \mathrm{ml} / \mathrm{min}$ :
$\quad 2$ days
Clinical observation
Careful haemostasis
Patient Blood Management
General measures
e.g. avoidance of hypothermia; volume therapy
Severe/life-threatening
bleeding
Laboratory analyses
pre-op: blood count, renal function
intra-op: blood count

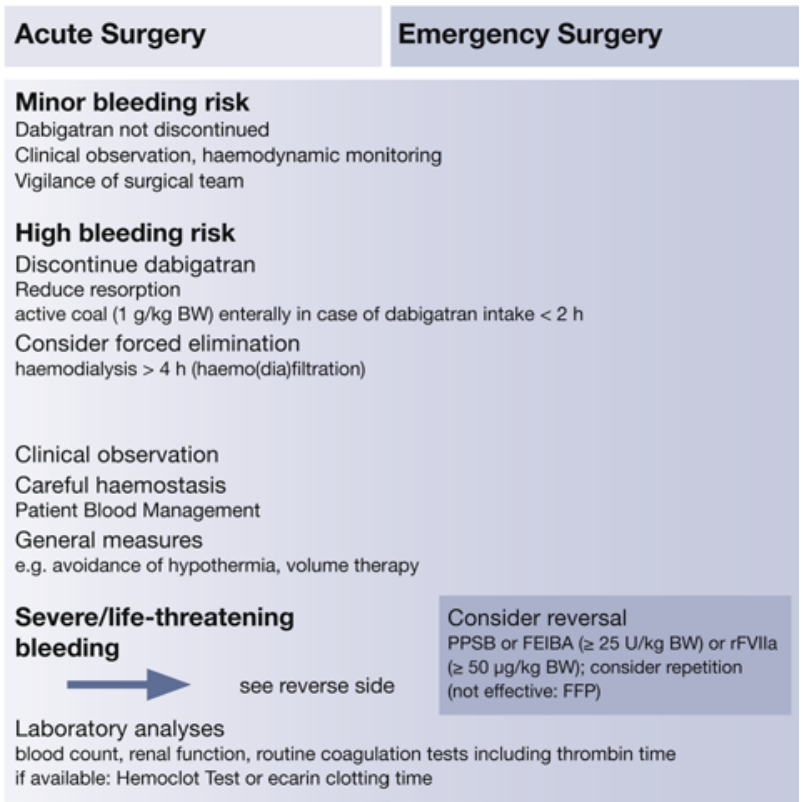

\section{Measures not recommended}

In view of the limited efficacy of fresh frozen plasma (FFP) to correct perioperative bleeding [29] and abnormal laboratory coagulation test results [30] the administration of FFP to reverse dabigatran-induced haemorrhages cannot be recommended.

\section{Perioperative management of dabigatran-treated patients}

Recommended strategies are summarised in Fig. 2.

\section{Elective interventions}

Surgical interventions should be classified in terms of their bleeding risk.

\section{Minor interventions}

In the case of minor interventions with a low bleeding risk it is recommended to continue administration of vitamin $\mathrm{K}$ antagonists [2, 3]. Analogously, dabigatran can also be continued in such cases [3]. During the intervention the theatre staff should make full use of available measures to ensure effective haemostasis and thus avoid excessive blood transfusions. The ward staff should be made fully aware of the risk of postoperative complications (haemorrhages) to ensure rapid recognition and correction.

\section{Major interventions}

In major interventions the bleeding risk is either due to the extent of foreseeable haemorrhage or its critical location (e.g. intracranial). Normal coagulation during major surgery and the early postoperative phase is seen as an important factor of patient safety. Accordingly, discontinuation of vitamin $\mathrm{K}$ antagonists and, where necessary, bridging with low-molecular-weight heparins is recommended $[2,3]$. Similarly, dabigatran may be discontinued. Whether bridging with heparins should be performed in the case of NOACs is still controversial. The authors of the present recommendations do not recommend bridging when NOACs are discontinued for the periods stipulated in the MAA documentation to prevent a possible increase in perioperative bleeding risk. However, if the thromboembolic risk is higher CHADS $_{2}$-Vasc Score $\geq 4$ ) and surgery requires discontinuation of dabigatran for more than 5 days, a bridging therapy with lowmolecular-weight heparin may be an option [11].

At what time dabigatran should be discontinued preoperatively will depend on the patient's current renal function [31]. In patients with a normal renal elimination facing a low-risk intervention a 2-day interval may be sufficient to preclude a clinically relevant residual effect of dabigatran during surgery. In the case of patients with a reduced renal elimination (creatinine clearance $<50 \mathrm{ml} / \mathrm{min}$ ) and a high-risk intervention dabigatran should be suspended for at least 4 days to prevent the intraoperative risk of residual anticoagulation.

Particularly in the case of major interventions the theatre staff should make full use of available measures to ensure effective haemostasis and thus avoid excessive blood transfusions. The ward staff should be made fully aware of the risk of postoperative complications (haemorrhages or thromboses) to ensure rapid recognition and correction.

\section{Laboratory tests}

Pre-operative renal function tests (creatinine clearance according to the Cockroft-Gault formula or calculating 
the glomerular filtration rate according to the MDRD formula) help determine the necessary interval before discontinuation of dabigatran administration.

Pre-operative blood counts or haemoglobin/haematocrit assays may detect the presence of anaemia, and a subsequent differential diagnosis and correction may enhance tolerance to perioperative bleeding [3]. This recommendation is in line with the concept of patient blood management [32]. An intra-operative and post-operative blood count analysis (including a platelet count) or, if the same is not readily available, the determination of haemoglobin/haematocrit values by means of blood gas analysis is recommended since it may serve as an indication for erythrocyte transfusion and can help avoid transfusions as soon as the individual transfusion trigger is exceeded.

The success of discontinuing vitamin $\mathrm{K}$ antagonists can be checked by means of the target value of INR (preoperatively mostly $<1.4$ ). Analogously, it would be desirable to obtain direct evidence that a safe plasma level has been reached or that the biological anticoagulatory effects of dabigatran have been eliminated. A dabigatran-sensitive coagulation test shortly prior to surgery might provide information on the extent of residual pharmacological anticoagulation [4]. The residual effect of dabigatran cannot be quantified by means of routine coagulation tests (global tests such as aPTT, PT, INR).

\section{Strategies not recommended}

Prophylactic administration of coagulation factor concentrates is not recommended for elective interventions since the operative trauma would compound the pre-existing risks of thromboembolism and acute-phase reaction with yet another prothrombotic stimulus in the form of the concentrates. Our recommendation, as described above in the context of acute bleeding, is to consider the administration of coagulation factor concentrates only in cases of severe intra-operative or postoperative haemorrhage.

\section{Elective interventions under regional anaesthesia}

Dabigatran for postoperative thrombosis prevention has only been approved for elective hip and knee joint replacement. In these cases the intervention may be performed under neuraxial regional anaesthesia: The epidural catheter is put in place prior to starting the postoperative administration of the prophylactic dose of dabigatran (110 mg Praxada ${ }^{\circledR} 2-4 \mathrm{~h}$ postoperatively, followed by $1 \times 220 \mathrm{~mm}$ Praxada ${ }^{\circledR}$ per day). Dabigatran should only be administered after removal of the catheter, in the interest of patient safety with a delay of at least $2 \mathrm{~h}$. According to the current recommendations based on pharmacokinetics the catheter may also be removed after a dabigatran withdrawal interval of $26 \mathrm{~h}$, and the next dose of dabigatran should be given, at the earliest, 4-6 $\mathrm{h}$ after removal of the catheter $[33,34]$. In the absence of study data, locoregional anaesthesia or the neuraxial catheter technique should not be used in patients for whom a rapid resumption of the administration of therapeutic doses of dabigatran $(2 \times 150 \mathrm{mg}$ or $2 \times 110 \mathrm{mg}$ Praxada ${ }^{\circledR}$ per day) has been envisaged.

Acute and urgent major interventions (within $24 \mathrm{~h}$ )

\section{Administration of dabigatran}

In the case of acute or urgent (semi-elective) major surgery with a relevant risk of bleeding (e.g. fractures near the hip, revision of septic joints, urgent tumour surgery) it is imperative to establish exactly when dabigatran was last administered: If the time interval recommended for elective major surgery cannot be respected on account of the urgency of the intervention, dabigatran therapy should at least be interrupted as soon as the indication for surgery has been established. If dabigatran was last given within the last 1 or $2 \mathrm{~h}$, reduction of resorption by means of oral activated coal may be attempted. Prior to high-bleeding-risk interventions it might be reasonable to reduce dabigatran by means of haemodialysis for $>4 \mathrm{~h}$.

\section{Basic measures}

Patient monitoring should comply with the measures outlined in the severe bleeding section above.

Symptomatic treatment of slight, massive, life-threatening and organ-threatening haemorrhages should be in line with the severe bleeding and life-threatening or organ-threatening bleeding section above.

Administration of coagulation factor concentrates should only be considered individually in the case of massive bleeding.

\section{Laboratory tests}

TT can be used to determine whether a residual dabigatran effect is still to be expected immediately before or in the course of an urgent or acute surgical intervention. Normal TT values may exclude the presence of a clinically relevant residual dabigatran effect. It is advisable to measure TT at two points in time to assess possible variations in the findings. If the TT is prolonged, a dabigatran-sensitive test should be performed as outlined in the mild bleeding section above: adapted thrombin time (e.g. Hemoclot ${ }^{\circledR}$ Test) or ecarin clotting time (ECT).

Particularly in the case of massive bleeding repeated blood counts are recommended to ensure targeted transfusion. Routine coagulation tests, and possibly also complementary rotational thromboelastometry/thromboelastography (especially for the diagnosis of hyperfibrinolysis) should be performed repeatedly to permit targeted correction of (especially) secondarily acquired coagulopathies $[3,22,35]$. 


\section{Emergency interventions}

\section{Administration of dabigatran}

In the case of peracute interventions that cannot be delayed and carry a high bleeding risk in terms of extent and location (e.g. ruptured hollow organs or vessels, traumatic brain injury, polytrauma) no further dose of dabigatran should be administered once the need for surgery has been established. In principle, emergency interventions on patients receiving dabigatran should be delayed as long as it is medically acceptable.

\section{Basic measures}

Patient monitoring should comply with the measures outlined in the severe bleeding section above.

Symptomatic treatment of slight, massive, life-threatening and organ-threatening haemorrhages should be in line with the severe bleeding and life-threatening or organ-threatening bleeding sections above. As soon as the first clinical symptoms of severe bleeding become apparent, reversal by FEIBA, rFVIIa or PCC should be considered in line with life-threatening or organ-threatening bleeding section. Forced elimination by haemodialysis (or haemo(dia)filtration, in which case both the effectiveness and the necessary duration of application are still in doubt) might be difficult under emergency surgery conditions and, in the case of polytrauma, in patients undergoing diagnostic imaging. As a matter of principle, emergency interventions should not be delayed on account of forced dabigatran elimination or reversal measures.

If the gastrointestinal tract is intact, dabigatran adsorption may be reduced without major delay by administering activated coal via a stomach tube in place. In patients whose history taken in an emergency situation fails to reveal the circumstances and time of dabigatran intake, external sources of information (statements of relatives etc.) may be significant.

\section{Laboratory tests}

The recommendations given in the acute and urgent major interventions section apply.

As regards the collective of trauma patients under dabigatran, physicians should refer to the European and Austrian Guidelines [21, 22].

Final comment. Randomised clinical trials are highly warranted to prove the suggested treatment options above and, finally, to define safe and efficacious therapeutic interventions and indicative laboratory testing in patients with or at risk for dabigatran-induced bleeding. Until this evidence is available registries may help us to establish patient-oriented care. The 'NOAC line' at www.oegari.at offers an electronic database to which anonymised cases of NOAC-induced bleeding and its management can be added, irrespective of the success or failure of the measures taken.

\section{Conflict of interest}

Sibylle Kozek-Langenecker received honoraria for lectures and travel reimbursement from Baxter, Boehringer Ingelheim, Biotest, CSL Behring, Novo Nordisk, Octapharma, TEM Innovations. Walter-Michael Halbmayer received honoraria for lectures or consultation from Bayer, Boehringer-Ingelheim, Pfizer Corporation, Roche Diagnostics, Siemens Healthcare, Stago.

\section{Open Access}

This article is distributed under the terms of the Creative Commons Attribution Noncommercial License which permits any noncommercial use, distribution, and reproduction in any medium, provided the original author(s) and the source are credited.

\section{References}

1. Fugate JE, Rabinstein AA, McBane RD, Lanzino G. Dabigatran: a primer for neurosurgeons. World Neurosurg. 2012 Jun 19. doi:pii:S1878-8750(12)00639-0. 10.1016/j. wneu.2012.06.019 (Epub ahead of print).

2. Guyatt GH, Akl EA, Crowther M, Gutterman DD, Schuünemann HJ, American college of chest physicians antithrombotic therapy and prevention of thrombosis panel. Executive summary: antithrombotic therapy and prevention of thrombosis, 9th ed: american college of chest physicians evidence-based clinical practice guidelines. Chest. 2012;141(Suppl 2):7S-47S.

3. Kozek-Langenecker S, Afshari S, Albaladejo P, Santullano CA, De Robertis E, Filipescu D, Fries D, Görlinger K, Haas T, Imberger G, Jacob M, Lancé M, Llau J, Mallett S, Meier J, Rahe-Meyer N, Samama CM, Smith A, Solomon C, Van der Linden P, Wikkelsø A, Wouters P, Wyffels P. Guidelines on the management of severe perioperative bleeding. Eur J Anaesthesiol. 2013;30(6):270-382.

4. Weltermann A, Brodmann M, Domanovits H, Eber B, Gottsauner-Wolf M, Halbmayer WM, Hiesmayr JM, Kyrle PA, Längle F, Roithinger FX, Watzke H, Windhager R, Wolf C, Zweiker R. Dabigatran in patients with atrial fibrillation: perioperative and periinterventional management. Wien Klin Wochenschr. 2012;124(9-10):340-7.

5. Cheng JW, Vu H. Dabigatran etexilate: an oral direct thrombin inhibitor for the management of thromboembolic disorders. Clin Ther. 2012;34(4):766-87.

6. Kreutz R. Pharmakologie neuer oraler Antikoagulantien. Grundlage für rationale Entscheidungen. Klinikarzt. 2012;41(S1):10-5.

7. Spannagl M, Bauersachs E, Debus ES, Gawaz M, Gerlach H, Haas S, Hach-Wunderle V, Lindhoff-Last E, Riess H, Schellong S, Schinzel H, Bode C. Therapie mit DabigatranPeriinterventionelles Management und Interpretation von Gerinnungstests. Hämostaseologie. 2012;32:294-305.

8. www.akdae.de; Leitfaden der Arzneimittelkommission der deutschen Ärzteschaft. Orale Antikoagulation bei nicht valvulärem Vorhofflimmern. Empfehlungen zum Einsatz der neuen Antikoagulantien Dabigatran (Pradaxa) und Rivaroxaban (Xarelto). Version 1.0, September 2012.

9. Samama CM. New anticoagulants: pharmacology and clinical studies. Wien Med Wochenschr. 2011;161(3-4):54-7.

10. Stangier J, Rathgen K, Stähle H, Gansser D, Roth W. The pharmacokinetics, pharmacodynamics and tolerability of dabigatran etexilate, a new oral 2 thrombin inhibitor, in healthy male subjects. Br J Clin Pharmacol. 2007;64(3):292-303. 
11. Sauer H, Wankmüller $H$, Leschke $M$. Blutungsmanagement, perioperatives und periprozedurales Bridging: Vorschlag praktischer Strategien für die neuen oralen Antikoagulantien. Klinikarzt. 2012;41:26-32.

12. Connolly SJ, Ezekowitz MD, Yusuf S, Eikelboom J, Oldgren J, Parekh A, Pogue J, Reilly PA, Themeles E, Varrone J, Wang S, Alings M, Xavier D, Zhu J, Diaz R, Lewis BS, Darius H, Diener HC, Joyner CD, Wallentin L, RE-LY steering committee and investigators. Dabigatran versus warfarin in patients with atrial fibrillation. N Engl J Med. 2009;361(12):1139-51.

13. Camm AJ, Lip GY, De Caterina R, Savelieva I, Atar D, Hohnloser SH, Hindricks G, Kirchhof P, ESC Committee for Practice Guidelines (CPG), Bax JJ, Baumgartner H, Ceconi C, Dean V, Deaton C, Fagard R, Funck-Brentano C, Hasdai D, Hoes A, Kirchhof P, Knuuti J, Kolh P, McDonagh T, Moulin C, Popescu BA, Reiner Z, Sechtem U, Sirnes PA, Tendera M, Torbicki A, Vahanian A, Windecker S, Document Reviewers, Vardas P, Al-Attar N, Alfieri O, Angelini A, Blömstrom-Lundqvist C, Colonna P, De Sutter J, Ernst S, Goette A, Gorenek B, Hatala R, Heidbüchel H, Heldal M, Kristensen SD, Kolh P, Le Heuzey JY, Mavrakis H, Mont L, Filardi PP, Ponikowski P, Prendergast B, Rutten FH, Schotten U, van Gelder IC, Verheugt FW. 2012 focused update of the ESC guidelines for the management of atrial fibrillation: an update of the 2010 ESC guidelines for the management of atrial fibrillation. Developed with the special contribution of the European Heart Rhythm Association. Eur Heart J. 2012;33(21):2719-47.

14. Halbmayer WM, Weigel G, Quehenberger $P$, et al. Interference of the new oral anticoagulant dabigatran with frequently used coagulation tests. Clin Chem Lab Med. 2012;50(9):1601-5. doi:10.1515/cclm-2011-0888.

15. Lindahl TL, Baghaei F, Blixter IF, Gustafsson KM, Stigendal L, Sten-Linder M, Strandberg K, Hillarp A, Expert group on coagulation of the external quality assurance in Laboratory Medicine in Sweden. Effects of the oral, direct thrombin inhibitor dabigatran on five common coagulation assays. Thromb Haemost. 2011;105(2):371-8.

16. Omran H, Bauersachs R, Rübenacker S, Goss F, Hammerstingl C. The HAS-BLED score predicts bleedings during bridging of 2 oral anticoagulation. Results from the national multicentre BNK Online bridging registry (BORDER). Thromb Haemost. 2012;108(1):65-73.

17. Lip GY, Nieuwlaat R, Pisters R, Lane DA, Crijns HJ. Refining clinical risk stratification for predicting stroke and thromboembolism in atrial fibrillation using a novel risk factorbased approach: the euro heart survey on atrial fibrillation. Chest. 2010;137(2):263-72.

18. Schulman S, Kearon C, Kakkar AK, et al. Extended use of dabigatran, warfarin, or placebo in venous thromboembolism. N Engl J Med. 2013;368(8):709-18.

19. Schulman S, Kearon C, Kakkar AK, et al. Dabigatran versus warfarin in the treatment of acute venous thromboembolism. N Engl J Med. 2009;361:2342-52.

20. Hébert PC, Wells G, Blajchman MA, Marshall J, Martin C, Pagliarello G, Tweeddale M, Schweitzer I, Yetisir E. A multicenter, randomized, controlled clinical trial of transfusion requirements 2 critical care. Transfusion requirements in critical care investigators, canadian critical care trials group. N Engl J Med. 1999;340(6):409-17.
21. Rossaint R, Bouillon B, Cerny V, Coats TJ, Duranteau J, Fernández-Mondéjar E, Hunt BJ, Komadina R, Nardi G, Neugebauer E, Ozier Y, Riddez L, Schultz A, Stahel PF, Vincent JL, Spahn DR, Task force for advanced bleeding care in trauma. Management of bleeding following major trauma: an updated European guideline. Crit Care. 2010;14(2):R52.

22. Fries D, Innerhofer P, Perger P, Gütl M, Hofmann N, Kneifel W, Neuner L, Pernerstorfer T, Pfanner G, Schöchl H, Ziegler B, Kölblinger C, Kozek-Langenecker SA. Gerinnungsmanagement bei traumatisch bedingter Massivblutung. AINS. 2010;45:552-61.

23. Cotton BA, McCarthy JJ, Holcomb JB. Acutely injured patients on dabigatran. N Eng J Med. 2011;365:2038-40.

24. Weitz JI, Quinlan DJ, Eikelboom JW. Periprocedural management and approach to bleeding in patients taking dabigatran. Circulation. 2012;126(20):2428-32.

25. Pezborn E, Trabandt A, Selbach K, Tinel H. Prothrombin complex concentrate reverses the effects of high-dose rivaroxaban in rats (Abstract). Pathophysiol Haemost Thromb. 2010;37:A10-OC251.

26. van Ryn J, Stangier J, Haertter S, Liesenfeld KH, Wienen W, Feuring M, Clemens A. Dabigatran etexilate-a novel, reversible. oral direct thrombin inhibitor: interpretation of coagulation assays and reversal of anticoagulant activity. Thromb Haemost. 2010;103(6):1116-27.

27. Eerenberg ES. Reversal of rivaroxaban and dabigatran by prothrombin complex concentrate. Circulation. 2011;124:1573-9.

28. Baron TH, Kamath PS, McBane RD. Management of anithrombotic therapy in patients undergoing invasive procedures. N Engl J Med. 2013;368:2113-24.

29. Kozek-Langenecker S, Sorensen B, Hess J, Spahn DR. Clinical effectiveness of fresh frozen plasma compared with fibrinogen concentrate: a systematic review. Critical Care. 2011;15:R239.

30. Abdel-Wahab O, Healy B, Dzik W. Effect of fresh frozen plasma transfusion on prothrombin time and bleeding in patients with mild coagulation abnormalities. Transfusion. 2006;46:1279-85.

31. Ortel TL. Perioperative management of patients on chronic antithrombotic therapy. Hematology Am Soc Hematol Educ Program. 2012;2012:529-35.

32. Goodnough LT, Shander A. Special article: current status of pharmacologic therapies. Anesth Analg. 2013;116:15-34.

33. Regionalanästhesie unter gerinnungshemmender Medikation. Empfehlungen der Arbeitsgruppe perioperative Gerinnung der ÖGARI. http://www.oegari.at/web_files/ dateiarchiv/116/Regionalanästhesie\%20und\%20Gerinnungshemmer\%202013.pdf. Last access 24 Sep 2013.

34. Gogarten W, Vandermeulen E, Van Aken H, Kozek S, Llau J, Samama M. Regional anaesthesia and antithrombotic agents: recommendations of the European Society of Anaesthesiology. Eur J Anaesthesiol. 2010;27:999-1015.

35. Afshari A, Wikkelsø A, Brok J, Møller AM, Wetterslev J. Thrombelastography (TEG) or thromboelastometry (ROTEM) to monitor haemotherapy versus usual care in patients with massive transfusion. Cochrane Database Syst Rev. 2011;(3):CD007871. doi:10.1002/14651858.CD007871. 